\title{
Demographic Features of Patients with Extremity and Spine Fractures in Emergency Departments
}

Kenan Koca, Ömer Erşen, Serkan Akpancar, Faruk Akyıldız, Levent Gürer

Clinic of Orthopedic Surgery, Gülhane Training and Research Hospital, Ankara, Turkey

\begin{abstract}
Aim: Fractures are a major source of disability in all age groups; however, little is known about their epidemiology despite being quite a few studies on this subject. The aim of this study was to identify the frequency, gender, and seasonal distributions of fractures in an emergency department.

Materials and Methods: Patients who had been admitted to an emergency department because of extremity and spine problems were included in this study. Physical examinations, radiographs, ultrasonography, computed tomography, and magnetic resonance images were recorded. All demographic data such as age and gender, and other data, including season and history, were collected retrospectively. Diagnoses and treatment types (conservative or surgery) were evaluated.

Results: Between January 2012 and January 2014, 190.986 patients ( 95.619 males and 95.367 females) with various complaints were admitted to an emergency ward. After assessment of 32.300 patients who had pain in an extremity or the spine, 4.036 of them were diagnosed with fractures, with a total of 4.301 fractures being diagnosed. The average age of the patients who presented symptoms in an extremity or the spine was 36.2 years, and the gender ratio (men/ women) was 60:40. The most common fractures were at the radius (15.6\%), and the least common fractures were at the sesamoid bones $(0.04 \%)$.
\end{abstract}

Conclusion: This study showed that $17 \%$ of the patients admitted to the emergency ward had extremity or spinal complaints and $2.2 \%$ of the patients had fractures. These epidemiological data may be relevant for physicians working in emergency departments when evaluating trauma patients.

Keywords: Demographics, fractures, emergency department

\section{Introduction}

Fractures are a major source of disability in all age groups; however, little is known about their epidemiology despite being quite a few studies on this subject. The knowledge of fracture incidence is important for the planning of treatment, to define training priorities, and to gain an understanding of orthopedic and trauma surgery. This study was conducted at a major trauma center that provides health services to patients of all age groups and is responsible for the inpatient and outpatient care of their injuries.

Epidemiology brings together all the knowledge of common diseases that occur in different groups. Epidemiological information is used to plan and evaluate strategies to prevent diseases and guide the management of patients $(1,2)$. Epidemiological knowledge of fractures is critical for determining the necessary measures to prevent the most common fractures, which is required to develop effective treatment strategies and training programs.
In emergency departments, there is little knowledge about the frequency and types of fractures in the patient population, and the factors that affect their distribution in Turkey. This study will provide a comprehensive perspective for emergency physicians to develop strategies for the most prevalent fractures in specific age groups, to prevent systemic complications due to major fractures and to guide the management of patients.

The purpose of this report to is summarize the available evidence on gender, age, and seasonal distribution of fractures to make recommendations for future needs and research opportunities.

\section{Materials and Methods}

This was a retrospective, single-center study conducted in an emergency department during the period from $1^{\text {st }}$ January, 2012 to $1^{\text {st }}$ January, 2014. The study was conducted in Keçiören, a district of Ankara in Turkey. The climate of this area varies through the year. The

This study was presented at the 50 ${ }^{\text {th }}$ Congress of the European Society for Surgical Research, 10-13 June 2015, Liverpool, United Kingdom.

Correspondence to: Serkan Akpancar e-mail: drserkanakpancar@gmail.com

Received: 09.11.2016 • Accepted: 13.01.2017

(C) Copyright 2017 by Emergency Physicians Association of Turkey - Available online at www.eajem.com

DOI: 10.5152/eajem.2017.57966 
Table 1. Frequency, gender ratio, treatment options and mean patient age for each type of fracture

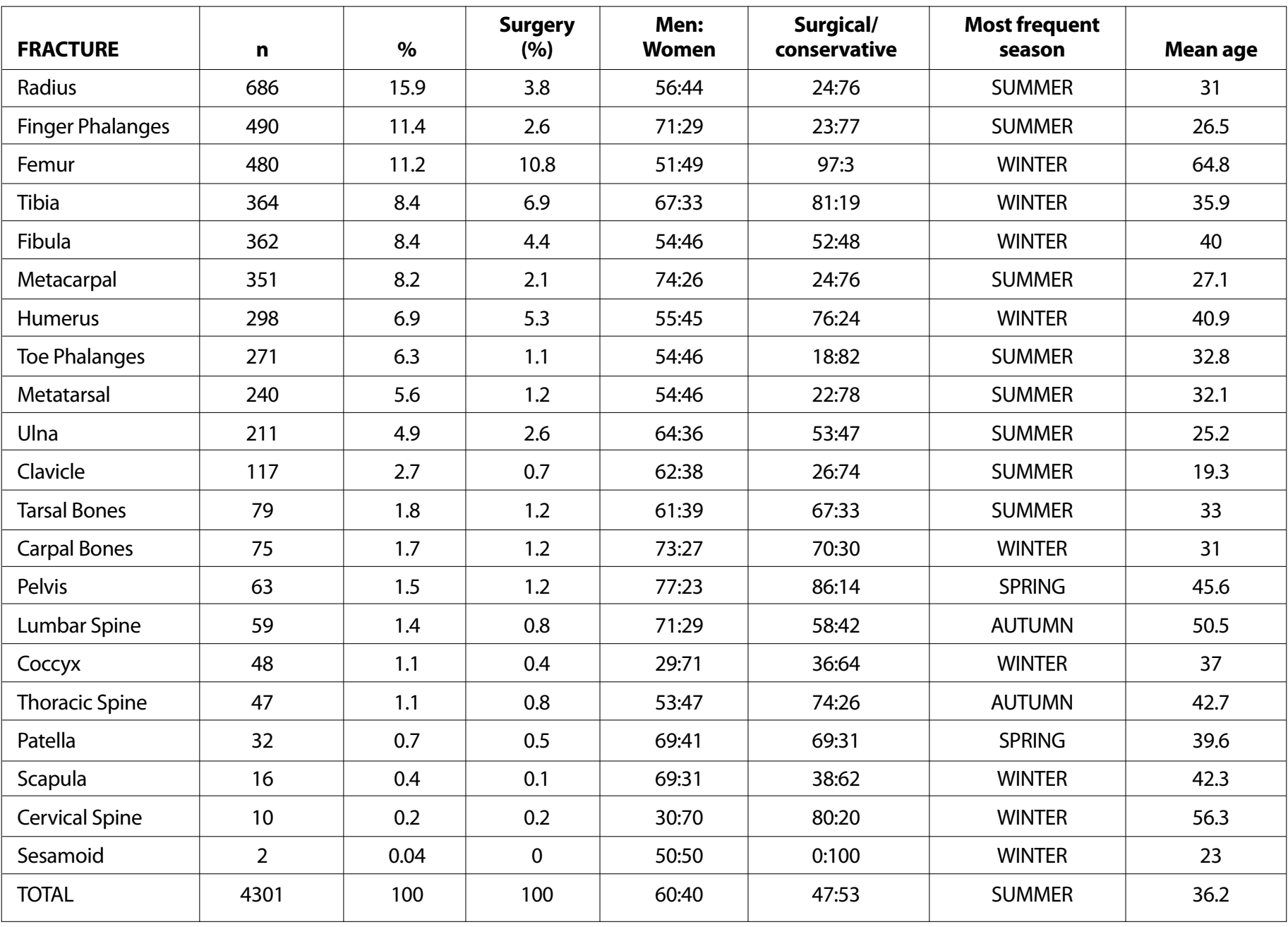

Table 2. Frequencies of carpal, phalangeal, toe and tarsal bones

\begin{tabular}{|l|c|c|c|c|}
\hline Fracture & $\begin{array}{c}\text { The most } \\
\text { common } \\
(\%)\end{array}$ & $\begin{array}{c}\text { The second } \\
\text { most common } \\
\text { (\%) }\end{array}$ & $\begin{array}{c}\text { The third } \\
\text { most common } \\
\text { (\%) }\end{array}$ & $\begin{array}{c}\text { The } \\
\text { rarest } \\
\text { (\%) }\end{array}$ \\
\hline Carpal Bones & $\begin{array}{c}\text { Scaphoid } \\
(89)\end{array}$ & $\begin{array}{c}\text { Trapezium } \\
(4)\end{array}$ & $\begin{array}{c}\text { Triquetrium } \\
(3)\end{array}$ & $\begin{array}{c}\text { Pisiform } \\
(0)\end{array}$ \\
\hline Tarsal Bones & $\begin{array}{c}\text { Calcaneus } \\
(55)\end{array}$ & $\begin{array}{c}\text { Talus } \\
(20)\end{array}$ & $\begin{array}{c}\text { Navicular } \\
(15)\end{array}$ & $\begin{array}{c}\text { Cuboid } \\
(1)\end{array}$ \\
\hline Metacarpals & $5 .(59)$ & $4 .(18)$ & $1 .(10)$ & 2. (4) \\
\hline Metatarsals & $5 .(63)$ & $4 .(12)$ & $3 .(9)$ & $1 .(8)$ \\
\hline Finger Phalanges & $5 .(33)$ & $4 .(24)$ & $1 .(17)$ & 2. (10) \\
\hline Toe Phalanges & $1 .(35)$ & $5 .(31)$ & $4 .(16)$ & $3 .(5)$ \\
\hline
\end{tabular}

average temperature is $23^{\circ} \mathrm{C}$ in summer and $-2^{\circ} \mathrm{C}$ in winter (3). The number of patients that received treatment in the hospital during 2014 was 872.025 . Patients were first evaluated by emergency doctors, and then, those with suspected fractures were evaluated by orthopedic and traumatology consultants. The suspected extremities were initially examined by physical examination, and then, two plain $X$-ray radiographs were taken. The patients who were suspected of having a fracture (not detected) were evaluated by computed tomography and subjected to radiological expert opinion. All patients
Table 3. Distribution of the fractures according to the anatomical region

\begin{tabular}{|l|c|c|c|c|}
\hline Fracture & $\begin{array}{c}\text { The most } \\
\text { common } \\
\text { side } \\
(\%)\end{array}$ & $\begin{array}{c}\text { The second } \\
\text { most common } \\
\text { side } \\
(\%)\end{array}$ & $\begin{array}{c}\text { The third } \\
\text { most common } \\
\text { side } \\
(\%)\end{array}$ & $\begin{array}{c}\text { The } \\
\text { rarest } \\
(\%)\end{array}$ \\
\hline Radius & $\begin{array}{c}\text { Distal } \\
(80)\end{array}$ & $\begin{array}{c}\text { Proximal } \\
(10)\end{array}$ & $\begin{array}{c}\text { Diaphysis } \\
(9)\end{array}$ & $\begin{array}{c}\text { Diaphysis } \\
(9)\end{array}$ \\
\hline Femur & $\begin{array}{c}\text { Proximal } \\
(70)\end{array}$ & $\begin{array}{c}\text { Diaphysis } \\
(18)\end{array}$ & $\begin{array}{c}\text { Distal } \\
(12)\end{array}$ & $\begin{array}{c}\text { Distal } \\
(12)\end{array}$ \\
\hline Humerus & $\begin{array}{c}\text { Proximal } \\
(45)\end{array}$ & $\begin{array}{c}\text { Distal } \\
(37)\end{array}$ & $\begin{array}{c}\text { Diaphysis } \\
(18)\end{array}$ & $\begin{array}{c}\text { Diaphysis } \\
(18)\end{array}$ \\
\hline Pelvis & $\begin{array}{c}\text { Ramus Pubis } \\
(38)\end{array}$ & $\begin{array}{c}\text { Acetabulum } \\
(23)\end{array}$ & $\begin{array}{c}\text { Sacrum } \\
(21)\end{array}$ & $\begin{array}{c}\text { Iliac crest } \\
(18)\end{array}$ \\
\hline
\end{tabular}

who had been diagnosed with a fracture were included in the study. The distribution of fractures according to age group, gender, frequency, applied treatment, and seasons is presented in Table 1-3 and Figure 1, 2.

All data was transferred to Microsoft Excel and analyzed using the Statistical Package of Social Sciences version 15 (SPSS Inc., Chicago, IL, USA) software package. A descriptive analysis was primarily applied. Clinical data were presented as numbers, percentages, and means. The distributions of data were subject to certain year intervals. 


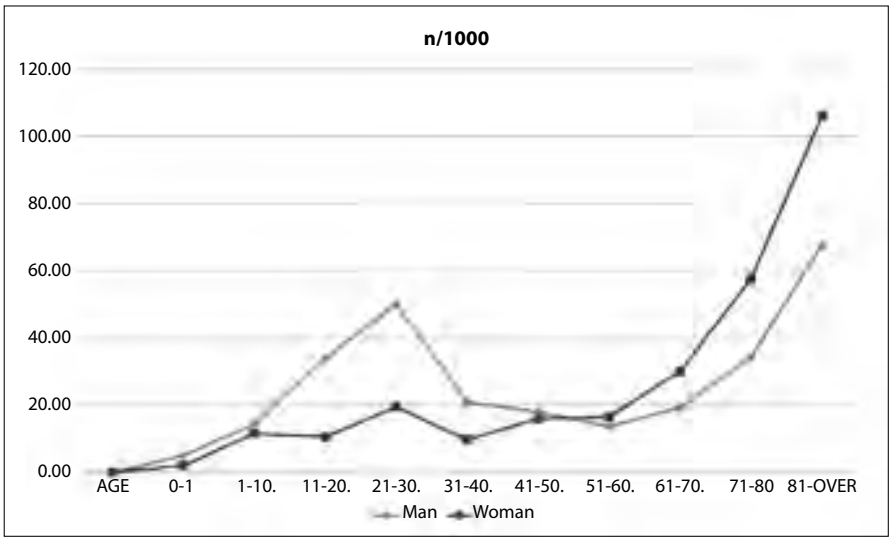

Figure 1. Age and gender distribution of fractures

\section{Results}

Between 2012 and 2013, 190.986 patients (95.619 males and 95.367 females) with various complaints were admitted to the emergency department. After assessment of 32.300 patients who complained of pain in the extremities or the spine, 4.036 of them were diagnosed with fractures, with a total of 4.301 fractures being diagnosed. The incidence of fractures on the total population was 4.6/1.000/year. The mean age of the patients was 36.2 years, with a gender ratio of 60:40 (male:female). The age and gender distribution of fractures according to each age decade is shown in Figure 1. A slightly undulating frequency in women is observed up to 60 years, with a rapid increase thereafter. In men, the pattern is different; there is an increased incidence in young men who are in their 30s that gradually falls until about 60 years of age. It then rises again, although the peak for older males is lower than for older females. The highest incidence of fracture in women is between 21 and 30 years and after 80 years of age. It is similar to men as there are two similar peaks between 21 and 30 years and after 80 years of age. Table 1 presents data on frequency and gender ratio, treatment options of all fractures observed in the emergency department. The most prevalent fractures were the radius fractures (15.6\%) and the least common were the sesamoid bone fractures $(0.04 \%)$. All sacrum fractures and most of the femur, pelvis, tibia, and cervical spine fractures were treated surgically. All sesamoid fractures and most of the metatarsal, finger phalanx, radius, and clavicle fractures were treated conservatively. The mean patient age for the metacarpal, finger phalanx, ulna, and clavicle fractures was less than 30 years and these could be considered as juvenile fractures. Most of the fractures occurred in men, mainly resulting from high-impact traumas, such as exercise, work casualties, car crash, and squeezing injuries. The mean patient age for the femur, humerus, cervical spine, and pelvis fractures was over 40 years and could be considered as old-age fractures. From the sixth decade onwards, most of the fractures occurred in women and were due to low-impact trauma that resulted in major fractures, usually caused by falling from a standing height. Fractures were most frequent during the summer and least likely to occur in the autumn. Weight-bearing fractures as well as human fractures of large bones, such as the femur, tibia, and fibula, occurred mostly during the winter, while fractures of small bones occurred mostly during the summer. Table 2 shows the frequency of carpal, phalangeal, and tarsal bone fractures. Amongst the carpal bones, the scaphoid was the most commonly broken bone, and the pisiform, the least. Amongst the tarsal bones, the calcaneus was the most commonly broken bone, and

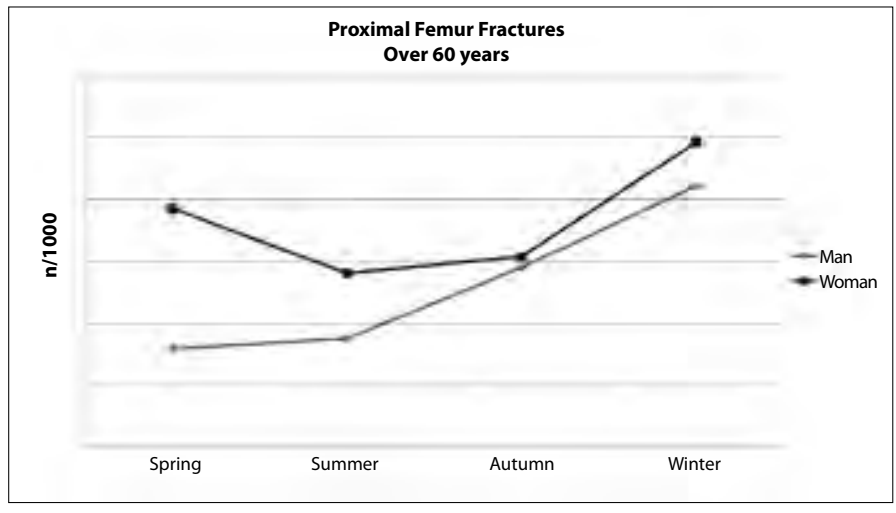

Figure 2. Age and seasonal distribution of proximal femur fractures over 60 years of age

the cuboid, the least. The fifth metatarsal, metacarpal, and finger phalanges were the most commonly broken bones, along with the first of the toe phalanges. Table 3 portrays the distribution of the fractures according to the anatomical region. The distal end of the radius, proximal end of the femur, proximal end of the humerus, and the pubic ramus of the pelvis were the most fractured sites. Figure 2 shows the age and seasonal distribution of the proximal femur fractures for patients over 60 . In women above 60 , fractures of the proximal femur occurred more than in men during all seasons. In the spring, fracture rates in women were 2.43 times higher than those in men, whereas, in autumn, the rates in women were similar to those in men.

\section{Discussion}

Gender, age, and seasonal distributions of fractures, the frequency of each type of fractures and the factors that affect the distribution of the fractures were investigated in this study.

In this study, the average age (40.7 years) of the patients with fractures is quite different from the average age (49.1 years) reported in other epidemiological studies $(4,5)$. This is related to the socioeconomic structure and the different young/elderly ratio in different countries. In this survey, the lower average age ( 36.2 years) was partially due to a younger population in Turkey. Agreement with the literature in terms of $60 \%$ of the patients being male was observed (6). Upon analyzing the overall age and gender frequency curves for females ( $40 \%$ of the cases), a slight undulating frequency was noted until menopause with a rapid apparent increase thereafter, and the percentage of fractures in this age group was higher than in men. This is similar to the type of distributions observed in the literature for women, i.e., unimodal, with a peak appearing around menopause, and increasing over the last decades of life (7). In men, the distribution is represented by a bimodal curve, which is again in agreement with the literature (8). The highest incidence of fractures took place in women in the age range of 21-30 years, especially in active individuals, due to high-impact trauma related to sports activities, crushing, and squeezing injuries, and in the over 80 years group because of inactivity, such as patients with low-impact trauma due to osteoporosis (9). Also, there was an increased incidence in patients of around 60 years old.

According to Johansen et al. (9) fractures of the metacarpals, metatarsals, and finger phalanges are not associated with age. However, fractures of the hip, spine, humerus, and pelvis are more common in the elderly, especially in females. These results agree with the work presented here, with the femur, humerus, spine, and pelvis fractures all occurring in patients over 40 years old. These were fractures associat- 
ed with age, more common in the elderly, and were acquired through low-impact trauma. The metacarpal, finger phalanx, ulna, and clavicle fractures mostly occurred in patients younger than 30 years, and were considered as juvenile fractures. Most of the fractures occurred in men primarily from daily activities, workplace injuries, sports, car crash, and squeezing injuries. From the sixth decade onwards, most of the fractures occurred in women and were because of low-impact trauma due to osteoporosis that resulted in major fractures.

Fractures were most frequent during summer and least frequent during autumn. However, weight-bearing fractures and human fractures of long bones, such as the femur, tibia, and fibula, were most prevalent during the winter, whereas fractures of small bones occurred mostly in the summer. The climatic conditions of the area where the study was conducted are ideal for presenting a seasonal distribution of fractures, as there are four distinct seasons. All the sacrum (100\%) fractures, and most of the femur (97\%), pelvis (86\%), tibia (81\%), and cervical spine (80\%) fractures were treated surgically. All the sesamoid and most of the metatarsal, finger phalanx, radius, and clavicle fractures were treated conservatively.

Studies suggest that osteoporotic fractures are increasing and mainly occur in women. Up to 10 different fracture types are considered to be potentially osteoporotic (10). Proximal femur fractures are one of the representative fractures that can indicate osteoporosis. Fractures occurring in patients over 60 account for the majority of hospitalization and mortality events (11). In this study, $70 \%$ of the femur fractures occurred on the proximal end, and the majority of these fractures were observed in patients over 60 , probably as a result of osteoporosis (12). It is known that the mortality rate is increased in patients who have already suffered a hip fracture within the first year following the fracture event $(13,14)$. This is because of comorbidities, advanced age, and actual fracture stress impact on overall health due to fracture. The distribution of proximal femur fractures according to seasons is shown in Figure 2. Fractures occurred more in women than in men in all seasons. In spring, the rate of fractures for women was 2.43 times higher than that for men; however, the rate decreased in summer. The rates leveled off in autumn, followed by an increase in winter again. This demonstrates that immobilization and sun deprivation lead to osteoporotic fractures much more frequently in women than in men.

\section{Study limitations}

The limitations of this study were retrospective nature and there are many shortcomings in this study of orthopedic epidemiology in Turkey. In an attempt to correctly define the epidemiology of fractures in the local population, a study should be conducted with individuals visiting only one orthopedic trauma unit.

\section{Conclusion}

By analyzing the data related to 4.301 fractures in 4.036 patients admitted to the emergency services of the Gülhane Military Medical Academy, the frequency of fractures according to age group, gender, and season were determined. The knowledge of fracture incidence is important for the planning of treatment, to establish priorities in training, and to gain an understanding of orthopedic traumatology.

In Turkey, osteoporotic fractures are increasing in patients over the age of 50, especially in women. Immobilization and sun deprivation in winter and spring result in osteoporotic fractures in women. This clearly has significant implications for the detection, prevention, and treatment of osteoporosis and the prevention and treatment of osteoporotic fractures. Efforts are potentially geared towards educating the population and, consequently, reducing osteoporosis rates.

Further epidemiological studies are needed for treatment initiatives. In an attempt to correctly define the epidemiology of fractures in the local population, all individuals participating in a study should visit only one orthopedic trauma unit in Turkey.

\section{Ethics Committee Approval: N/A}

Informed Consent: N/A.

Peer-review: Externally peer-reviewed.

Acknowledgements: The authors would like to thank Harun Yasin Tüzün, Hasan Turgut, Nuray Can, Murat Durusu and Ibrahim Arziman for their valuable contributions.

Conflict of Interest: No conflict of interest was declared by the authors.

Financial Disclosure: The authors declared that this study has received no financial support.

\section{References}

1. Aschengrau A, Seage G. Essentials of Epidemiology in Public Health. Jones \& Bartlett Learning; 2008.

2. Pearce N. Traditional epidemiology, modern epidemiology, and public health. Am J Public Health 1996; 86: 678-83. [CrossRef]

3. Sensoy S, Demircan M, Ulupınar Y, Balta I. Climate of Turkey. 2007. Devlet Meteoroloji Iş̧leri Genel Müdürlüğü, 13 Feb. 2009 Available at: http://www. dmi.gov.tr/index.aspx.

4. Braga Junior MB, Das Chagas Neto FA, Porto MA, Barroso TA, Lima ACM, Silva SM, et al. Epidemiologic profile and satisfaction level of patients presenting musculoskeletal trauma assisted in a public emergency hospital in Brazil. Acta Ortop Bras 2005; 13: 137-40.

5. Court-Brown CM, Caesar B. Epidemiology of adult fractures: a review. Injury 2006; 37: 691-7. [CrossRef]

6. de Albuquerque AL, de Sousa Filho PG, Braga Junior MB, Cavalcante Neto Jde S, de Medeiros BB, Lopes MB. Epidemiology of fractures in patients from small towns in Ceará treated by the SUS. Acta Ortop Bras 2012; 20: 66-9.

7. Sobania LC, Tatesuji BS, Pacheco CES. Acidentes de tráfego, um problema de saúde pública: análise de 160 pacientes acidentados e internados em hospitais de pronto socorro. Rev Bras Ortop 1989; 24: 13-22.

8. Court-Brown CM, Caesar BC. The epidemiology of fractures. In: Bucholz RW, Heckman JD, Court-Brown CM, eds. Rockwood \& Green's Fractures in Adults. 6th ed. Philadelphia, PA: Lippincott Williams \& Wilkins; 2006.p.96-113.

9. Johansen A, Evans RJ, Stone MD, Richmond PW, Lo SV, Woodhouse KW. Fracture incidence in England and Wales: a study based on the population of Cardiff. Injury 1997; 28: 655-60. [CrossRef]

10. Mandıracıoğlu A. Demographic characteristics of the elderly population in Turkey and the world. Ege J Med 2010; 4: 39-45.

11. Abrahamsen B, Van Staa $T$, Ariely $R$, Olson $M$, Cooper C. Excess mortality following hip fracture: a systematic epidemiological review. Osteoporos Int 2009; 20: 1633-50. [CrossRef]

12. Silveira VA, Medeiros MM, Coelho-Filho JM, Mota RS, Noleto JC, Costa FS, et al. Hip fracture incidence in an urban area in Northeast Brazil. Cad Saude Publica 2005; 21: 907-12. [CrossRef]

13. Kanis JA, Oden A, Johnell O, De Laet C, Jonsson B, Oglesby AK. The components of excess mortality after hip fracture. Bone 2003; 32: 468-73. [CrossRef]

14. Kanis JA, Odén A, McCloskey EV, Johansson H, Wahl DA, Cooper C. A systematic review of hip fracture incidence and probability of fracture worldwide. Osteoporos Int 2012; 23: 2239-56. [CrossRef] 